\title{
O Cinema como Instrumento Didático para a Abordagem de Problemas Bioéticos: uma Reflexão sobre a Eutanásia
}

\author{
Cinema as a Teaching Tool for Discussing \\ Bioethical Issues: Reflections on Euthanasia
}

Anielle Avelina Dantas ${ }^{I}$

Carlos Henrique Martins Maria Socorro Ramos Militão ${ }^{I I}$

\section{PALAVRAS-CHAVE \\ - Humanidades. \\ - Educação Médica. \\ - Cinema como Assunto \\ - Bioética. \\ - Eutanásia.}

\section{KEYWORDS \\ - Humanities. \\ - Education, Medical. \\ - Motion Pictures as Topics. \\ - Bioethics. \\ - Euthanasia}

\section{Recebido em: 23/11/2009}

Reencaminhado em: 30/05/2010

Aprovado em: 22/08/2010

69

REVISTA BRASILEIRA DE EDUCAÇÃO MÉDICA
${ }^{I}$ Universidade Federal de Uberlândia, Uberlândia, MG, Brasil.

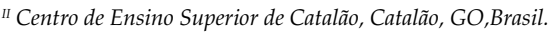

O ensino da ética é necessário à formação dos alunos do curso de Medicina, pois o cuidado da saúde dos indivíduos e das populações pressupõe ações e decisões que devem ser permanentemente avaliadas de modo racional com respeito às suas reais e efetivas repercussões. As artes cinematográficas podem estimular a avaliação crítica e o entendimento efetivo das narrativas e necessidades únicas dos pacientes. O objetivo do presente estudo é mostrar que a análise estruturada de um filme comercial pode constituir uma atividade instrucional facilitadora para a concretização de objetivos educacionais relativos ao ensino da bioética e, em particular, dos problemas morais concernentes à eutanásia. Foi realizada uma interpretação macro e microanalítica do filme Mar Adentro e identificaram-se exemplos de situações e oportunidades de ensino-aprendizagem. O critério de seleção das cenas se pautou na capacidade de estas revelarem conteúdos e situações que possam estimular uma reflexão acerca dos dilemas morais/bioéticos relativos ao direito à vida. A exibição de um filme seguida da discussão de cenas pode ser utilizada como instrumento pedagógico significante para atingir objetivos educacionais humanísticos dos currículos dos cursos de Medicina.

Ethics is an indispensable subject in undergraduate medical training, since care for individual and collective health presupposes actions and decisions that require permanent, rational evaluation of the real and effective repercussions. Cinema can stimulate critical evaluation and effective understanding of patients' unique narratives and needs. The aim of this study was to demonstrate that structured analysis of a commercial movie can serve as a teaching activity that facilitates the achievement of educational objectives in the teaching of bioethics, particularly the moral issues involved in euthanasia. A macro and micro-interpretation of the film Mar Adentro (The Sea Inside) was performed, identifying examples of situations and opportunities for teaching-learning. The criterion for selecting scenes was their capacity to reveal contents and situations that could stimulate reflection on moral and bioethical dilemmas pertaining to the right to life. A film screening followed by discussion of the scenes can be used as a significant teaching tool for achieving humanistic educational objectives in the undergraduate medical curriculum. 


\section{INTRODUÇÃO}

O caráter exclusivamente técnico na formação dos profissionais das ciências da saúde deu lugar à preferência por práticas educacionais inovadoras que transcendem a incorporação de conhecimentos necessários à compreensão do processo saúde-doença. Tais práticas consideram relevante a abordagem holística do paciente. Com efeito, verifica-se frequentemente uma insatisfação apontada pelos pacientes com a maneira fria e desumana como são tratados pelos profissionais da saúde, que assumem uma postura alienada e reducionista, uma vez que priorizam o tratamento das doenças e não dos doentes e desprezam a complexa dimensão biopsicossocial do adoecimento. Este cenário das práticas de saúde vigentes exige uma transformação do processo ensino-aprendizagem que possibilite ao futuro profissional o entendimento do paciente como um todo em seu adoecer ${ }^{1,2}$.

A matriz flexneriana de educação médica impõe fragmentação dos saberes e das práticas e falha na compreensão da complexidade do processo saúde-doença, que incide no campo daquilo que é humano em seu sentido mais pleno - os encontros humanos. Trata-se, portanto, de incluir as humanidades médicas na formação do aluno para dar conta da sensibilidade e da subjetividade dos encontros entre os doentes e os futuros médicos ${ }^{3}$.

Os professores estão familiarizados com um fenômeno antigo: estudantes de Medicina, por exemplo, que iniciam seus estudos repletos de idealismo e altruísmo, mas que posteriormente começam a mostrar sinais decepcionantes, tornando-se menos empáticos e até mesmo cínicos. Isto é resultado de uma deficiência em sua formação humanística, associada à dificuldade de vivenciar situações conflituosas com que se deparam na fase final do curso, visto que as explicações unicamente racionais são insuficientes para os problemas de seus pacientes. Os encontros nos cenários das práticas na área da saúde são caracterizados por alto grau de ambiguidade, incerteza e imprevisibilidade, que demandam habilidades profissionais específicas. A inclusão das humanidades nos currículos dos cursos de Medicina contribui, por exemplo, para o desenvolvimento de habilidades comunicativas necessárias para melhor compreensão das narrativas dos pacientes e do próprio discurso técnico-científico ${ }^{4,5}$.

Um fator que dificulta a proposição de um conteúdo ideológico para a formação humanística do médico, por exemplo, se relaciona às mudanças históricas no significado social e ético da atividade médica ${ }^{6}$. Essa formação humanística precisa preparar o médico para saber ouvir o homem (o ser humano) ${ }^{7}$ vitimado pela doença, razão pela qual o paciente busca por ajuda. Nesse sentido, a educação do profissional da saúde precisa sair da dimensão essencialmente técnica para incorporar valores humanistas, fundamentais na percepção da alteridade. As humanidades vêm para encorajar os alunos a identificar, explorar, desenvolver e manter seus valores pessoais, desenvolvendo nos estudantes habilidades na comunicação, incluindo uma percepção mais aguçada das dimensões éticas de suas práticas e condutas terapêuticas ${ }^{8}$.

Blasco ${ }^{9}$ ressalta a importância de educar a afetividade do aluno no processo educacional, uma vez que as emoções dele não podem ser desprezadas nesse processo. Assim, o aluno necessita que o seu mundo - seu universo de relações afetivas, seus valores culturais e sentimentos - seja representado e compreendido. A valorização da afetividade no processo ensino-aprendizagem favorece a elaboração do raciocínio lógico, que, por conseguinte, se refletirá positivamente nas condutas profissionais do futuro médico. Dessa forma, é possível uma educação médica eficaz que alcance os objetivos de uma formação humanística, ética e responsável do educando?.

A experiência, vivenciada concretamente ou representada, dos dilemas morais abordados é fundamental no processo educacional, pois determina a motivação e a busca ativa do conhecimento. As imagens e emoções apresentadas na tela constituem caminhos alternativos que estimulam a racionalidade ${ }^{9-13}$.

O cinema pode desempenhar várias funções (pedagógica, interpretativa e experimental) na educação médica, que contribuem para a reflexão sobre temas bioéticos ${ }^{13}$. Ele pode ser um instrumento facilitador para a comunicação entre professor e aluno por ser uma ferramenta didática que vai ao encontro do padrão cultural predominante na atualidade, uma cultura baseada nas imagens, nos sentimentos, na chamada "cultura do espetáculo" (há uma conotação negativa desse referencial que mereceria atenção). Ele acaba por otimizar a possibilidade de ver, ouvir e experimentar algo não vivenciado na realidade ou algo vivenciado concretamente, mas de forma protegida. Assim, tanto as narrativas ficcionais quanto as não ficcionais (documentários) oferecem ao estudante a oportunidade de sair da mera abstração para um retrato recortado do concreto por meio de uma representação artística dos conceitos e temas abordados na teoria. Elas traduzem formas de vida como satisfação de desejos (ficção) ou como representação de valores sociais e culturais (documentários) ${ }^{14}$. Filmes de ficção tornam visíveis e audíveis desejos, medos, anseios e pesadelos, e expressam aquilo que é, pode vir a ser ou nunca será. Podem, portanto, indicar infinitas ideias e pontos de vista que podemos aceitar ou rejeitar. Por outro lado, os documentários "representam aspectos de um mundo que já ocupamos e compartilhamos" e podem, portanto, proporcionar realidades e visões de mundo a serem exploradas e compreendidas. Com efeito, o cinema possibilita ao aluno e ao educador refletir, 
reavaliar preconceitos e ressignificá-los por meio de histórias e narrativas alheias. Nesse sentido, o cinema propicia que o aluno recrie valores humanistas preexistentes, tão importantes pessoal e profissionalmente em benefício dos futuros pacientes. Pode-se dizer que o cinema desempenha um papel de "educador sentimental".

Outro aspecto importante se relaciona à oportunidade que o cinema cria de estabelecer um diálogo variado, complexo, multidisciplinar, menos formal, fora dos moldes e limitações impostos pela teoria. Esses diálogos geram discussões capazes de externar as experiências pessoais dos alunos, estimulando o debate e propiciando um novo olhar do educando para o objeto de estudo. Vale enfatizar que a temática abordada a partir de um filme apresentado aos alunos não resulta numa discussão a ela limitada. Cabe também ao educador nesse processo de ensino-aprendizagem aproveitar a ocasião e oferecer oportunidades para que os alunos reflitam acerca de si (autoconhecimento) e do mundo que os cerca9 ${ }^{9}$.

Nessa perspectiva, o presente estudo busca conciliar a inserção das disciplinas de humanidades nos cursos de graduação das ciências da saúde com a abordagem de tema bioético polêmico, a eutanásia, utilizando o cinema como ferramenta educacional. O objetivo é promover o debate, estimular a reflexão dos alunos e, principalmente, gerar, por parte deles, o raciocínio crítico e a autonomia intelectual. No futuro, serão esses alunos que decidirão sobre as questões de vida e morte e para isto precisam ser devidamente formados e capacitados. Tal formação transcende a mera reprodução técnica de conceitos apreendidos na teoria.

\section{METODOLOGIA}

Este trabalho foi desenvolvido a partir de uma análise macro e microanalítica do filme Mar Adentro ${ }^{15}$ e buscou destacar as questões relativas à eutanásia retratadas nesse filme. Realizou-se a seleção de algumas cenas, que foram descritas de forma sintetizada, e delas foram destacados os diferentes olhares dos personagens sobre o tema. O critério de seleção pautou-se pela sua capacidade (força) de revelar conteúdos e situações que podem estimular a reflexão acerca dos dilemas morais/ bioéticos a respeito do direito à vida, em geral, e da eutanásia, em particular, nos diversos cenários do processo de ensino-aprendizagem dos cursos de Medicina.

A polêmica em torno da eutanásia é retratada em vários filmes. A escolha do filme Mar Adentro ${ }^{15}$ se fez por ele retratar de maneira real, sensibilizadora e conflitante a discussão acerca da eutanásia. Além disso, é interessante sua abordagem multidimensional, pois desloca o debate do ambiente hospitalar para as diferentes esferas da vida do personagem.

\section{Sinopse do filme Mar Adentro}

Mar Adentro conta a história verídica de Ramón Sampedro Cameán, interpretado pelo ator Javier Bardem, um galego que aos 25 anos ficou tetraplégico em decorrência de um acidente ocorrido no momento em que se lançou de uma rocha ao mar. A irreversível fratura da sétima vértebra da coluna cervical o deixou tetraplégico. Condenado a viver numa cama, Ramón inicia, logo após tomar conhecimento do diagnóstico médico, uma luta pela conquista do direito à eutanásia. Sua luta durou aproximadamente 30 anos e constitui uma busca não apenas pelo direito a sua morte, mas também pela dignidade de sua vida ${ }^{16}$.

A chegada de duas mulheres à vida de Ramón alterará sua existência. Júlia (Belén Rueda) é uma advogada disposta a apoiá-lo em favor da eutanásia, motivada por sua identificação com ele devido à sua condição de portadora de uma síndrome degenerativa chamada Cadasil (Cerebral Autosomal Dominant Arteriopathy with Subcortical Infarts and Leukoencephalophaty $)^{17}$, doença vascular de herança autossômica dominante, causada por uma mutação do gene Notch3, situado no cromossomo 19, que tem como principais manifestações: enxaqueca, depressão, crises epiléticas e demência progressiva secundária que ocasiona múltiplos infartos cerebrais. Os sintomas dessa doença geralmente se iniciam na quarta década de vida do paciente e progridem com a perda gradativa dos movimentos. $\mathrm{O}$ interesse de Júlia pela causa de Ramón ocorre porque ambos estão condenados ao mesmo destino: à dependência de outrem e ao estágio vegetativo de vida. Rosa é uma vizinha que insiste em convencer Ramón a desistir de sua luta pela morte. A personalidade marcante de Ramón acaba por cativar as duas mulheres e fazê-las questionar os princípios que regem suas vidas, contrariando a intenção de Rosa de dissuadi-lo de seus objetivos. Esta, ao final, auxilia Ramón a praticar a própria morte, como prova de seu amor por ele.

\section{RESULTADOS E DISCUSSÃO}

Um detalhe importante a observar nesse filme é que a prática da eutanásia não depende de uma atitude médica nem de um profissional da área de saúde. O drama consiste na realização ou não do desejo do tetraplégico de morrer com a ajuda de uma pessoa que o ame a ponto de ajudá-lo nesse ato. Devido à ilegalidade da ação e ao fato de Ramón receber cuidados domiciliares da família, o drama ocorre fora do ambiente hospitalar. Essa observação é importante porque, na maioria dos debates sobre a eutanásia, o ambiente hospitalar e os profissionais da saúde aparecem com maior importância. Com efeito, os estudantes de Medicina podem, com a análise deste filme, refletir sobre a anonimização do morrer em clínicas e 
em hospitais, a perda da representação pública da morte e o afastamento de pacientes terminais de seus parentes e de seu ambiente doméstico e familiar ${ }^{18,19}$.

O termo eutanásia, apesar de significar etimologicamente "boa morte", traz consigo uma carga pejorativa, pela virtual associação histórica com o extermínio de velhos, doentes mentais ou deficientes físicos. O filme pode estimular os alunos dos cursos de Medicina a conceber os conceitos de eutanásia ativa, passiva e de suicídio assistido, além do princípio de futilidade decorrente da inutilidade (e da crueldade) do prolongamento de um tratamento que não apresenta expectativas de êxito e que, ao contrário, prolonga o sofrimento e desrespeita a vontade do paciente $\mathrm{e}^{20-22}$.

A complexidade do ser humano e sua possibilidade de reavaliar conceitos e mudar valores enraizados são explicitadas no filme, bem como a discussão acerca da responsabilidade ou corresponsabilidade de ajudar uma pessoa a lutar pelo direito à liberdade de manter ou pôr fim a sua vida. Assim, o filme apresenta de forma dramática a necessidade de colocar em pauta a discussão sobre os direitos considerados inalienáveis na sociedade atual, entre os quais não se incluem o direito ou liberdade de praticar a eutanásia. Regidos por valores cristãos, que se refletem na formulação de leis sociais consideradas laicas, a prática e o direito à eutanásia são condenados a convenções e tradições que trazem implicações que ferem o direito à dignidade da vida, contrariando o mesmo princípio que dá origem ao direito à vida. Isto porque corroboram a manutenção de uma vida permeada por sofrimentos psíquicos e físicos e privações de toda ordem. Nessa perspectiva, deve-se considerar e sublinhar para os alunos de Medicina a capacidade do ser humano de alterar sua existência, valores e formas de pensar à medida que também muda o contexto histórico e social.

A luta de Ramón pela morte contraria os familiares, que o cercam de amor e atenção. O mesmo acontece com seus advogados, que tentam, por todos os meios possíveis, auxiliá-lo na demanda jurídica por seus direitos. O dilema de valores é patente em diferentes níveis e entre os demais personagens. A trama do filme Mar Adentro, que versa sobre a vida e a liberdade, leva o telespectador a avaliar seus valores morais e aqueles que norteiam a vida humana em sociedade. A questão central do filme, que consiste no direito à vida, mas que inclui uma boa e serena morte, certamente pode contribuir para a compreensão pelos alunos do significado entre saber e morte, ou seja, "o saber acerca da própria finitude, quer dizer, da certeza de que um dia vamos morrer, e, por outro lado, o impetuoso e urgente não-querer-saber desse tipo de consciência" ${ }^{20}$.

Para uma análise microanalítica do filme, foram selecionadas sete cenas que podem ser utilizadas como ferramenta didática nos currículos médicos para alimentar reflexões acerca de dilemas morais relevantes como o da eutanásia.

Na primeira cena escolhida (0:06:13 a 0:08:21), a advogada Júlia pergunta a Ramón por que ele deseja morrer. A resposta é segura e contundente, pois a vida para ele, naquele estado, não é digna, não vale a pena. Além disso, aceitar a cadeira de rodas seria como aceitar migalhas do que foi sua liberdade: “você está aí sentada, a menos de dois metros. O que são dois metros? Uma viagem insignificante para qualquer ser humano. Bem. Para mim, esses dois metros necessários para eu poder chegar até você e te tocar são uma viagem impossível... uma quimera, um sonho. É por isso que quero morrer".

Nesta cena, a narrativa de Ramón nos remete ao evitado, mas necessário enfrentamento da morte e de sua intrínseca relação com a vida. Seu conceito de vida está ligado à dignidade e à qualidade de vida, abordadas de forma contundente. Esta cena pode ser útil durante a discussão do processo de morte e de morrer. A morte é percebida pelos médicos e pelos futuros médicos, em geral, como fracasso, especialmente pela disponibilidade de recursos tecnológicos sofisticados e eficazes para a manutenção da vida. Com efeito, o posicionamento do personagem principal pode auxiliar o professor de Medicina a conduzir uma reflexão acerca da ideia moderna de desmitologização da morte e do entendimento da morte como inexorável limite ao projeto iluminista de tudo controlar (inclusive a morte) por avanços técnicos da ciência moderna ${ }^{18,17}$.

Além disso, pode-se discutir o conceito e o significado de qualidade de vida, constantemente invocado como objetivo final dos cuidados paliativos e como referencial ou determinante do princípio de melhor interesse dos pacientes ${ }^{23}$. A recusa de Ramón em aceitar uma cadeira de rodas e a imagem de sua imobilidade - movimentar-se autonomamente é uma "viagem impossível" para ele - retratam a questão nuclear que percorre a ética biomédica: o que faz uma vida humana ter valor e, em particular, ter mais valor que outras (inclusive outras formas de vida)? Solicitar aos alunos que respondam a essa pergunta pode induzi-los a perceber que as decisões da vida prática e, portanto, as resoluções dos dilemas morais em Medicina dependem, em última análise, dessa resposta. Vale lembrar que esta é uma discussão essencialmente filosófica com imediata consequência prática, o que pode estimular os alunos a se aproximar das teorias filosóficas. Por outro lado, pensar no valor da vida humana remete também ao entendimento de que a prática médica (ou o cuidado da saúde) é mais clara e visível afirmação da sua expressão.

Noutra cena (0:30:10 a 0:31:49), Mark (Francesc Garrido), advogado de Ramón, argumenta perante os juízes do tribunal que o Estado que se diz laico deveria se livrar de "crenças me- 
tafísicas ou religiosas" para decidir quanto aos dilemas relativos ao direito à vida, como o suicídio assistido.

Esta cena possibilita uma discussão sobre os princípios que podem ser considerados quanto ao direito de decisão de retirar a vida por meio da eutanásia ou suicídio assistido: piedade médica, autonomia e justiça. Esses conceitos devem ser discutidos conforme os preceitos tradicionais bioéticos, o principialismo ${ }^{22}$, bem como outros sistemas da filosofia moral, como, por exemplo, o prescritivismo universal de Hare ${ }^{24,25}$ e o utilitarismo abordado nas análises de Peter Singer ${ }^{26}$. Os estudantes de Medicina têm aqui a oportunidade de se aproximar de referenciais ético-filosóficos importantes para a elaboração de um pensamento crítico que possibilite o entendimento da complexidade da abordagem (justificação moral) dos difíceis dilemas morais enfrentados pela medicina. Outra característica interessante na repercussão da demanda de Ramón é o impacto social que seu caso provocou na sociedade espanhola, promovendo a assinatura de um manifesto com milhares de assinaturas que endossavam o pedido de direito à eutanásia.

Outra cena (0:08:31 a 0:09:11) confirma o amadurecimento, durante anos, da decisão de Ramón. Os personagens Gené, Julia e Mark falam da decisão de Ramón, de quando ele os procurou e do fato de nunca ter hesitado em sua opção. Aqui é possível perceber que há em Ramón uma segura determinação ou decisão para o suicídio assistido, permitindo uma reflexão sobre as dificuldades quanto à distinção entre suicídio (e suicídio assistido) e eutanásia e as definições dos diferentes tipos de eutanásia (eutanásia ativa e passiva, voluntária e não voluntária) 20,22,27. Cabe perguntar aos alunos (e solicitar a fundamentação das respostas) se filmes como Mar Adentro ${ }^{15}$ e Menina de Ouro $^{28}$ são películas sobre eutanásia ou se a possibilidade de morte iminente e o sofrimento desesperador e irreversível (como no caso de Julia, a advogada de Ramón) são ingredientes necessários para querer morrer dignamente. A análise do filme Invasões Bárbaras ${ }^{29}$ pode também auxiliar o debate, uma vez que o personagem principal, um intelectual com doença terminal, se despede da vida de forma programada e festiva junto aos seus amigos, seu filho, sua ex-mulher e suas duas amantes. Outro aspecto que pode ser discutido na abordagem desta cena são as implicações legais para os que possam colaborar, na prática, com o suicídio assistido. Gené, mesmo se dispondo a assessorar Ramón em sua demanda, reflete em sua fala a responsabilidade legal que a questão impõe.

É possível, assim, identificar os principais elementos morais e legais que permeiam o debate acerca da eutanásia no processo ensino-aprendizagem. Pode-se também deslocá-lo para uma esfera talvez mais produtiva para a compreensão da eutanásia, ou seja, o conhecimento das experiências viven- ciadas pelas pessoas que desejam o término de suas vidas. Isto significa que desvelar a vulnerabilidade das motivações individuais e o papel das relações sociais pode auxiliar os alunos a se afastar da polarização acadêmica, por vezes estéril, durante a discussão dos dilemas morais relacionados ao direito à vida ${ }^{30,31}$.

Há uma cena (0:15:30 a 0:19:27), transcorrida no quarto de Ramón, quando ele recebe a primeira visita de Rosa (Lola Dueñas), que evidencia o contraste entre a vida expressa através dos olhos de Ramón, segundo Rosa, e seu desejo de morrer. Rosa o visita com a intenção de fazê-lo mudar de ideia. É possível nesta cena exemplificar para o aluno de Medicina uma realidade muito presente na prática médica: aspectos objetivos identificáveis pela observação rigorosa do paciente podem não traduzir sua real condição psicoemocional e sua subjetividade. Mesmo tendo vida em seus olhos, a morte prevalece o tempo todo no pensamento do personagem principal. Cabe perguntar ao aluno, com o objetivo de estimular o raciocínio lógico para a resolução de problemas bioéticos, se o fato de o tratamento possível a ser oferecido não corresponder ao interesse de Ramón (voltar a movimentar-se ou ter a vida de antes do acidente) ou não resultar em benefício da sua qualidade de vida (pelo menos da forma que ele deseja) é razão suficiente para justificar moralmente o pedido de suicídio assistido. Além disso, é importante discutir a questão da supremacia do corpo sobre a subjetividade, questionar o valor da vida e da existência relacionado à construção social, histórica e cultural. Assim, pode-se solicitar aos alunos que elaborem argumentos que possibilitem a Ramón reavaliar posturas, conceitos e "certezas" que possam promover uma mudança de atitude ou ressignificação do sentido da sua vida. Nesse momento, torna-se oportuna a exposição dos argumentos contrários à eutanásia para que se possa fazer uma abordagem oposta àquela apresentada no filme.

Outra cena (0:57:45 a 1:00:48) nos apresenta o diálogo entre José (Celso Bugallo), irmão do protagonista, Rámon, e seu pai Joaquín (Joan Dalmau). Nesse momento, Ramón diz que estar vivo é um ônus para a família, na tentativa de justificar a lógica de sua decisão. Com essa fala, Ramón expõe sua incapacidade de prover a si e a sua família, pois está desprovido de um valor capitalista primordial, que é a capacidade de trabalhar e se inserir no sistema. Encontra nesse argumento mais um motivo que justifica sua vontade de morrer. Insinua representar para a família uma fonte de gastos, além de não poder, diante da eventual morte do irmão, sustentar a família que tanto ama e que durante muitos anos cuidou dele. O "custo" da manutenção da vida e o impacto financeiro da manutenção de um tratamento de saúde nessas condições também são aspectos 
possíveis de discussão. Cabe aqui sublinhar aos alunos uma importante contribuição da ética compreendida por Foucault que se contrapõe às teorias clássicas. Ao contrário da tradição ética (filosófica ou religiosa), que privilegia as obrigações dos indivíduos para com os outros, para Foucault importa como o ser humano constrói sua subjetividade, de modo que a procura de certos valores para alcançar um estado de perfeição (uma experiência estética) incide no próprio sujeito ${ }^{29}$. A decisão de viver ou morrer deve repousar na capacidade de cada um usar sua liberdade por meio de um movimento interior de autoconhecimento. A moralidade popular, dominada por valores religiosos, e o aparato médico, fortemente burocratizado e instrumentalizado, são expressões de controle social da morte e do morrer. De forma sutil, a estrutura pública de saúde comanda quem deve e quando deve morrer, pois tem a posse das condições objetivas para decidir, por exemplo, quem terá a prioridade e o privilégio, num cenário de parcos e finitos recursos financeiros destinados à saúde, de ser cuidado em uma unidade de terapia intensiva. A ética em Foucault nos auxilia a compreender como a morte moderna escapa do controle privado. A intervenção médica que impede a morte desejada (por inanição) pelo protagonista do documentário Solitário Anôni$m o^{33}$ retrata de forma tocante essa realidade.

O filme Invasões Bárbaras ${ }^{29}$ também retrata, de maneira por vezes cínica e irônica, o enfrentamento da medicalização da morte e seu controle social. O cineasta Denys Arcand faz uma crítica sagaz ao Estado, à polícia, à Igreja e à família. Fugindo do trivial, o filme inova ao reunir todos, inclusive antigos amigos, amantes e ex-alunos, e aproveita para discutir valores éticos que permeiam nossa cultura, materialista e consumista, e que marginalizam o sentido da convivência humana. $\mathrm{O}$ encontro dos personagens proporciona o progresso ético individual. A morte do protagonista leva o espectador a reavaliar suas crenças e a perceber criticamente os valores morais de nossa época.

Noutra cena (1:04:42 a 1:10:22), Ramón recebe a visita do padre Francisco (José Maria Pou) — também tetraplégico - , que tenta convencê-lo, utilizando argumentos religiosos, de que é desejável viver mesmo naquela condição. O diálogo entre os personagens possibilita refletir sobre o papel e a influência dos valores religiosos (no caso, cristãos) na discussão dos dilemas morais relativos ao direito à vida. Ramón "desmascara" de forma sutil o verdadeiro interesse da Igreja pela vida, que, para ele, tem a função de legitimar sua função perante a sociedade e ressalta seu papel de sustentar a estrutura social. A religião aparece como responsável pela obstrução ao processo de legalização da eutanásia ao retirar do indivíduo a posse de sua vida e transferi-la para Deus.
É importante que o professor pondere que o indivíduo carrega uma carga de religiosidade e pode agir moralmente a partir da ideia de bem ou de mal (uma vez que a moral pertence ao campo da ação individual) e, assim, agir de acordo com sua formação moral, pois na formação de cada um há uma deontologia social implícita que prescreve condutas consideradas socialmente éticas, que influenciam suas ações. Pode-se, também, utilizar esse embate entre Ramón e o padre como ponto de partida para a discussão com os alunos a respeito da contraposição entre o princípio de santidade da vida, o princípio de autonomia e o conceito de qualidade de vida ${ }^{23,34-36}$. Nesse momento, é explícita a existência de uma dicotomia na discussão da eutanásia, que se polariza entre a sacralidade da vida (representada pela religião) e a qualidade de vida (discussão laica, fundamentada, em sua maior parte, em aspectos objetivos relacionados ao paciente). É oportuno, por exemplo, perguntar ao aluno a partir de uma afirmação do padre - "uma liberdade que elimina uma vida não é liberdade" - se a sacralidade secular da vida precede a autodeterminação dos indivíduos que desejam morrer ou que recusam tratamento em circunstâncias em que essa recusa resulta na morte. Cria-se, assim, espaço para a reflexão sobre esses princípios conflitantes e abre-se caminho para, após uma melhor compreensão teórica, tentar elaborar argumentações e justificativas morais para a defesa das respostas e das posições tomadas pelos alunos.

Esta cena revela uma opção diferente de enfrentamento das limitações físicas, já que o padre, também tetraplégico, encara a vida com uma perspectiva oposta à de Ramón. A partir das questões suscitadas nessa cena, os alunos podem se posicionar frente às opções de enfrentamento apresentadas pelos personagens e, por conseguinte, fortalecer seus argumentos na discussão das múltiplas subjetividades que interferem na percepção da polêmica.

O filme termina com a realização do desejo de Ramón, efetivado com a ajuda de Rosa (1:53:02 a 1:57:10) em Boiro, cidade onde essa personagem mora. A família de Ramón sofre com sua partida. Julia não se lembra de quem foi Ramón, devido ao avanço de sua doença. Na efetivação da eutanásia, Ramón toma todas as providências para evitar que Rosa se comprometa juridicamente. Ele escreve um testamento, em que detalha todas as ações anônimas que culminaram na realização de seu desejo e junto ao qual deixa um poema que escreveu, que encerra o filme.

O princípio da autonomia e a consideração do conceito de qualidade de vida podem fundamentar a concretização do desejo de morrer pelo não oferecimento de tratamento (omissão), quer por recusa do paciente em se tratar, quer por juízo do médico de que o tratamento não trará benefício, mesmo que 
essa opção resulte em morte. No entanto, estas justificativas não podem ser estendidas para que o médico auxilie (ação) o paciente em seu propósito de morrer, mesmo para o bem ou benefício deste. A identificação pelos alunos desta distinção legal entre omissões e ações poderá facilitar a compreensão dos limites impostos à eutanásia e ao suicídio assistido e da (não) diferença do ponto de vista moral entre morrer e deixar morrer.

Independentemente da opinião de cada aluno sobre o tema abordado, o filme traz elementos e pontos de reflexão referentes ao universo do paciente e sua doença. Nesse sentido, contribui para uma reavaliação dos valores pessoais de cada aluno e suas posturas diante dessa polêmica "demasiado humana". O professor pode usar esses elementos para educar futuros profissionais eticamente capacitados e fazê-los compreender que cada paciente é produto das relações sociais e das influências do ambiente em que se insere.

O debate sobre a eutanásia suscitado no filme deve ser analisado a partir de princípios bioéticos. Além disso, pode evidenciar o potencial do cinema para atender aos anseios intelectuais e críticos dos espectadores. Serve como um "degrau a mais" ao aluno das ciências da saúde na escalada para o conhecimento.

\section{CONCLUSÃO}

As Humanidades médicas desempenham uma função fundamental na educação dos alunos dos cursos das ciências da saúde. Quanto mais integradas estiverem aos currículos desses cursos de graduação, maiores serão os resultados positivos no tratamento dos futuros pacientes, uma vez recuperada a necessidade de considerar a dimensão humana da relação médico-paciente.

Ao retratar situações reais, polêmicas e conflituosas presentes na vivência dos futuros profissionais da saúde, o cinema pode constituir uma ferramenta educacional importante, pois, ao desvelar essas experiências vividas pelos personagens, motiva os estudantes a acompanhar histórias de vida que ainda não experimentaram (ou que irão experimentar). Essas narrativas oferecem oportunidades para uma reflexão sobre a complexidade do comportamento humano e suas implicações nas práticas profissionais dos futuros médicos. O cinema favorece uma abordagem menos tradicional da bioética e cria uma atmosfera propícia à interação do aluno com as polêmicas e novos problemas da assistência de saúde pós-moderna, revelando-se uma forma mais prazerosa e inteligente de levar o aluno a discutir as bases conceituais da bioética.

Embora a descrição das cenas represente muito pouco a grandiosidade destes filmes comerciais e a maneira sensibili- zadora como a eutanásia ou o suicídio assistido neles são representados, foi possível retirar vários elementos que podem servir como ponto de partida para que esse difícil dilema moral seja mais bem fundamentado e discutido por futuros médicos sob vários pontos de vista. Educar atitudes e afetividades supõe mais do que oferecer conceitos teóricos ou simples treinos; implica promover a reflexão, verdadeiro núcleo do processo ensino-aprendizagem que se deseja tornar humanizante. Nessas circunstâncias, o cinema ganha fôlego e importância.

APOIO: CNPq — processo 401802/2005-1 e FAPEMIG — PPM-00306-08

\section{REFERÊNCIAS}

1. Blasco PG, Gallian DMC, Roncoletta AFT, Moreto G. Cinema para o estudante de medicina: um recurso afetivo/ efetivo na educação humanística. Rev Bras Educ Med. 2005;29(2):119-28.

2. Tapajós R. O ensino da medicina através das humanidades médicas: análise do filme And the band played on e seu uso em atividades de ensino/ aprendizagem em educação médica. [tese] São Paulo; 2005. Doutorado [Tese] - Faculdade de Medicina da Universidade de São Paulo.

3. Marins JJN, Rego S, Lampert JB, Araújo JGC. Educação médica em transformação: instrumentos para a construção de novas realidades. São Paulo: Hucitec; 2004.

4. Bleakley A, Marshall R, Brömer R. Toward an aesthetic medicine: developing a core medical humanities undergraduate curriculum. J Med Humanit. 2006; 27(4)197-213.

5. Edgar A, Pattinson S. Need humanities be so useless? Justifying the place and role of humanities as a critical resource for performance and practice. Med Humanities. 2008;32(2)92-8.

6. Pessotti I. A formação humanística do médico. Medicina (Ribeirão Preto) 1996;29:440-8.

7. Scliar M. A paixão transformada: história da medicina na literatura. São Paulo: Companhia das Letras; 1996.

8. Evans M. Reflections on the humanities in medical education. Med Educ. 2002;36(6):508-13.

9. Blasco PG. Educação da Afetividade através do cinema. São Paulo: IEF; 2006.

10. Guilhem D, Diniz D, Zicka F, ed. Pelas Lentes do Cinema: Bioética e Ética em Pesquisa. Brasília: Ed. UnB; 2007.

11. Lumlertgul N, Kijpaisalratana N, Pityaratstian N, Wangsaturaka D. Cinemeducation: A pilot student project using movies to help students learn medical professionalism. Med Teach. 2009;31(7):e327-e332.

12. González-Blasco PG, Pinheiro TRSP, Rodríguez MFU, Calderón NMA. El cine en la formación ética del médico: un 
recurso pedagógico que facilita el aprendizaje. Persona y Bioética. 13(33):114-27.

13. Shapshay S. Bioethics at the movies. Baltimore: The Johns Hopkins University Pres; 2009.

14. Nichols B. Introdução ao documentário. Campinas: Papirus; 2005.

15. Mar Adentro. Direção: Alejandro Amenábar. Espanha:[s.n.]; 2004. 1 filme (125 $\mathrm{min})$, son, color.

16. Sampedro R. Cartas do Inferno. São Paulo: Planeta do Brasil; 2005.

17. Choi JC. Cerebral autosomal dominant arteriopathy with subcortical infarcts and leukoencephalopathy: a genetic cause of cerebral small vessel disease. J Clin Neurol. 2010;6(1):1-9.

18. Ariès P. História da morte no ocidente. Rio de Janeiro: Ediouro; 2003.

19. Gadamer HG. A experiência da morte. In: Gadamer HG. O caráter oculto da saúde. Rio de Janeiro: Vozes; 2006. p.68-76.

20. Batista RS, Schramm FR. Conversações sobre a "boa morte": o debate bioético acerca da eutanásia. Cad Saúde Pública. 2005;21(1):111-9

21. Batista RS. Eutanásia e compaixão. Rev Bras Cancerol. 2004;50(4):334-40.

22. Beauchamp TL, Childress JF. Princípios de Ética Biomédica. São Paulo: Loyola; 2002.

23. Kupperman JJ. Ethics and qualities of life. Oxford: Oxford University Press; 2007.

24. Hare RM. A linguagem da moral. São Paulo: Martins Fontes; 1996.

25. Hare RM. Ética: problemas e propostas. São Paulo: Ed. Unesp; 2003.

26. Singer P. Aética prática. 3 ed. São Paulo: Martins Fontes; 2002.

27. Mcmahan J. The ethics of killing. Oxford: Oxford University Press; 2002. p.455-503.

28. Million Dollar Baby. Direção: Clint Eastwood. EUA: Europa Filmes; 2005. 1 filme (133 min), son., color. Título em português: Menina de Ouro.
29. Les Invasions barbáries. Direção: Denys Arcand. Canadá: Europa Filmes; 2003. 1 filme (94 min), son., color. Título em português: As invasões bárbaras.

30. Parker M. End games: euthanasia under interminable scrutiny. Bioethics. 2005;19(5-6):523-36.

31. Gillis CM. Seeing the difference: an interdisciplinary approach to death, dying, humanities, and medicine. J Med Humanit. 2006;27(2)105-15.

32. Prado CG. Foucauldian ethics and elective death. J Med Humanit. 2003;24(3-4):203-11.

33. Solitário Anônimo. Direção: Débora Diniz. Brasil: Imagens Filmes; 2007. 1 filme (18 min), son., color.

34. Hale C. Recent thinking about end of life issues. Best Pract Res Clin Anaesthesiol. 2006;20(4):605-17.

35. Battin MP. The least worst death. Essays in bioethics on the end of life. Oxford: Oxford University Press; 1994.

36. Broome J. Weighing lives. Oxford: Oxford University Press; 2006. p. 241-53.

\section{CONTRIBUIÇÃO DOS AUTORES}

Anielle Avelina Dantas, participou na concepção e desenho deste estudo e da análise e interpretação dos dados assim como da redação deste texto. Carlos Henrique M. da Silva (orientador), participou na concepção e desenho deste estudo, bem como da revisão da redação do texto. Maria Socorro Ramos Militão (co-orientadora), participou na concepção da metodologia e revisão do manuscrito.

\section{CONFLITO DE INTERESSES}

Declarou não haver.

\section{ENDEREÇO PARA CORRESPONDÊNCIA}

Carlos Henrique Martins

Av. Rondon Pacheco, 3333 - apto. 103

Cazeca - Uberlândia

CEP 38400-050 - MG

E-mail: carloshm@netsite.com.br 